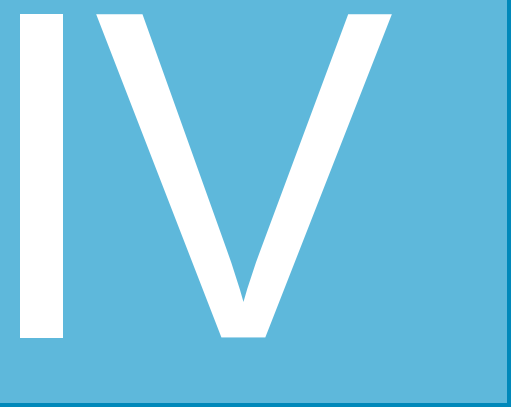

\title{
RELACIONES PÚBLICAS Y LOS VALORES MORALES CRISTIANOS
}

\section{Public Relations and the Christian Moral}

\section{István János Kovács Halay}

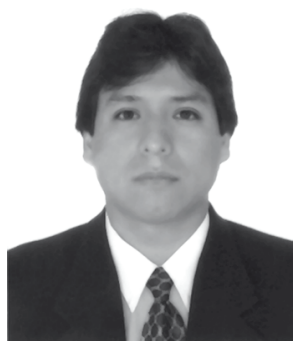

Licenciado en Ciencias de la Comunicación. Magíster en Administración Educativa y doctorando en Educación por la Universidad Peruana Unión. Actualmente se desempeña como docente de posgrado de la Universidad Peruana Unión. Es miembro directivo en calidad de Vocal Suplente de la Red Interamericana de Profesionales de Relaciones Públicas (Redirp). Ha sido ponente a nivel nacional e internacional en diversos congresos sobre temas de Relaciones Públicas, Educación, Publicidad y Marketing. 


\section{Resumen}

Las Relaciones Públicas constituyen un área de las ciencias de la comunicación en donde los valores morales y cristianos son esenciales para su desarrollo. Al tratarse de la buena relación que deben mantener diversas organizaciones con sus públicos y la sociedad en general, ésta debe basarse en la verdad, la honestidad y el respeto por la dignidad humana. Ninguna organización puede alcanzar su desarrollo a costa de la gente mediante acciones negativas que las puedan perjudicar. Se debe desarrollar junto con la sociedad, siguiendo el precepto que Jesucristo nos enseñó: "Ama a tu prójimo como a ti mismo". Se destaca la importancia de la fe, el perdón, la laboriosidad, la honestidad, la amistad y la verdad como los pilares fundamentales de unas Relaciones Públicas con responsabilidad social.

Palabras clave: Relaciones públicas, valores, fe, perdón, verdad, honestidad, responsabilidad social.

\section{Abstract}

The Public Relationship makes up an area of the communication sciences where the moral and Christian values are important in its development. All the social organizations that can be privates or public should keep the good relationship among its members, which must be based in the truth, the honesty, and the respect for the human dignity. No one organization can reach its development based in negative actions that can be very harmful for its members. The human relationship must development together to the society following the commandment that our Christ Lord taught us: "Love your neighbor as yourself." Here is stressed the importance of the faith, the forgiven, the honesty, the truth, the fellowship and other moral values. These are as a fundamental column in all the public relationship which should be adopted with social responsibility.

Keywords: Public relationship, faith, forgiven, honesty, social responsibility. 


\title{
Relaciones Públicas y los Valores Morales y Cristianos
}

\author{
"El profesional verdadero es aquél quien, además de dominar y \\ conocer el área al cual dedicó sus esfuerzos, tiene también un alto sentido \\ de los valores cristianos. No puede ser un profesional aquél que domina un \\ área del conocimiento humano sin valores. Por ello no existe profesión sin \\ valores".
}

\section{István J. Kovács Halay}

No existe una definición de consenso sobre lo que es valor. En todos los ámbitos, tanto personales como profesionales, aceptamos la existencia de valores, pero la controversia surge al analizar sobre su forma o existencia sobre nuestras actividades cotidianas.

Para las relaciones públicas, podemos considerar de vital importancia la aplicación de estos valores en el ejercicio de esta profesión, no como algo complementario, sino como una forma de vida que el profesional debe seguir tanto en su vida personal como profesional. En el primer aspecto predica con el ejemplo, mientras que en el segundo muestra una imagen impecable con mucha sensibilidad social, buen trato, conductas ejemplares que sirvan de guía para todos sus públicos. Pero, debe existir una gran coherencia entre lo que dice (telling) y lo que hace (doing), es decir, los hechos deben respaldar sus palabras. Los públicos apreciarán a aquella organización que sea transparente, sincera e integrada con ellos.

Existen tres concepciones sobre el significado de "valor". La concepción subjetivista es aquella que afirma que algo vale a medida que deseamos o sentimos agrado o aprobación hacia algo, por lo que las cosas en sí no tienen valor. El valor lo encontramos en las personas quienes las aprecian.

Respecto a la segunda concepción, que es la objetivista, se afirma que el "valor" es independiente a las experiencias humanas y que tiene identidad propia: es eterno, ideal, admirable y perfecto, y por ello nos sirve como patrón de conducta regulador sobre los objetos reales.

En tanto, los defensores de la tercera concepción sostienen que el "valor" es descrito bajo diversas perspectivas, siendo su definición flexible y amplia. Esto quiere decir que no podemos reducir la concepción del valor a una idea personalista sin que tenga un sustento en la realidad social en donde nos desarrollamos, ya que lo podemos apreciar en situaciones concretas en donde, como lo afirma Frondizi citado por Ramos (1998), se deja expresar la gran capacidad creativa del hombre. 
A la luz de esta tercera concepción, para las relaciones públicas, en consecuencia, hablar de valores tiene dos sentidos:

- Uno normativo, que nos guía hacia un ideal que es lograr que los públicos convivan armoniosamente con las organizaciones, y viceversa, basadas en el conocimiento mutuo y pleno entre ambas partes producto del ejercicio de un nivel superior de comunicación (véase el capítulo 4 del presente libro sobre el nivel meta-meta perceptivo).

- Otro aplicativo, en donde podemos desarrollar los valores morales en la anticipación y solución de problemas concretos de comunicación y relaciones que puedan tener las organizaciones con sus respectivos públicos, en donde, indudablemente, la capacidad creativa del profesional de Relaciones Públicas, quien sus ideales y su formación ético-moral lo podrá demostrar en el mundo real al resolver estos problemas.

\section{Las Relaciones Públicas en los Valores Morales}

\subsection{Las Relaciones Públicas y la vida}

La protección a la vida es una de las máximas expresiones valorativas en nuestro medio en la actualidad. Cuando vemos que algunas organizaciones, principalmente en los casos de las empresas mineras, no les interesan la salud ni el bienestar de las poblaciones aledañas a sus zonas de operaciones y dejan que muchos de ellos padezcan problemas graves de salud que comprometen seriamente su derecho a la vida, causan repudio y condena social.

El derecho a la vida del ser humano, contempla que éste pueda lograr su desarrollo sin vulnerar sus derechos básicos, como lo es a la salud, a la conservación del medio ambiente que le rodea, hechos que le permitan desenvolverse dignamente.

Ninguna organización, sea cual fuese su naturaleza, hoy en día puede ser aceptada si es que no hace algo en defensa de la vida, no solo del ser humano, sino también de las demás especies animales y vegetales que en conjunto forman el ecosistema que asegura la supervivencia del ser humano en sí. Ya han alzado sus voces de protesta muchas organizaciones ecológicas y de derechos humanos (como por ejemplo GREENPEACE) contra la forma inhumana de operar que tienen algunas organizaciones en nuestro mundo.

Juegan un rol fundamental en este sentido las Relaciones Públicas al buscar que las organizaciones asesoradas debidamente por ellas, respeten el derecho a la vida de toda especie, tanto la humana, como la animal o vegetal. Actualmente vivimos en una crisis ecológica mundial, en la cual muchas 
especies están en riesgo de extinción, e inclusive está en riesgo la existencia humana para los próximos años. Todo esto producto de la ambición desmedida por parte de algunas organizaciones poderosas que primaron sus propios intereses sobre los de sus prójimos.

El que no lleguemos a esos extremos de autodestrucción, serán de entera responsabilidad de nosotros mismos como seres humanos. Las relaciones públicas pretenden humanizar cada vez más el trabajo de todas las organizaciones, sean éstas grandes o pequeñas, todas comparten una gran responsabilidad social como lo es la defensa de la vida. La vida en si es el principal derecho de todo ser.

Actualmente, la defensa de la vida se convirtió en la principal finalidad del cumplimiento de la responsabilidad social que deben asumir todas las organizaciones que deseen obtener el concepto favorable por parte de la gente. En Lima, hace pocos años el parque zoológico (Parque de las Leyendas) se pidió que diversas instituciones y empresas privadas (así como también a diversos personajes económicamente solventes) se hicieran cargo de la protección de diversas especies animales. Muchas organizaciones acudieron al llamado e inclusive, dentro de su política de responsabilidad social, ayudan al desarrollo de investigaciones que permitan evitar la extinción de diversas especies en peligro. Es por eso que afirmamos que las organizaciones están llamadas a hacer historia en nuestra sociedad. Y qué mejor ganándose el respeto y la confianza de la gente a través de la defensa de la vida en nuestro mundo.

\subsection{Las Relaciones Públicas y la justicia (para la administración de la con- troversia pública)}

Al referirnos a la "justicia", se nos viene a nuestra mente darle a cada quien lo que le corresponde según sus acciones. Si las acciones que hacemos son buenas y están conforme a la moral, nos corresponderán en consecuencia reconocimientos y el logro de un concepto favorable hacia nosotros. En caso contrario, el mismo entorno social nos demandará y no cesará de presionar hasta que no recibamos lo que nos corresponde: la sanción por lo mal que hemos obrado. Cuando esto sucede, solemos escuchar por doquier la expresión "se hizo justicia" con gran regocijo social.

Entonces, a la luz de esta concepción, el ser humano busca siempre que le hagan justicia, sea para recibir algo que necesita y merece para vivir dignamente con el respeto a todos sus derechos, o como cuando siente que vulneran su dignidad, exigirá a la sociedad mediante sus autoridades a que dictaminen el castigo para quienes infringieron su dignidad. 
Recordemos, para tal efecto, que las relaciones públicas buscan el desarrollo de las organizaciones en concordancia con el respeto a la dignidad del ser humano. Esto equivale a decir que las Relaciones Públicas buscan orientar el desarrollo de toda empresa o institución con justicia, crecer conjuntamente con sus públicos y producto de este desarrollo repartir equitativamente estos beneficios, logrando así un equilibrio de intereses y en donde ambas partes se sientan conformes y ganadores.

En virtud de ello, solo si actuamos con sentido de justicia practicando en todo momento la equidad como norma de vida y de desarrollo, podremos alcanzar la felicidad en nuestro medio, alejando así los conflictos y las posibles crisis que se deriven de ellos que puedan perjudicar seriamente el desenvolvimiento de las organizaciones.

En relaciones públicas, una forma de actuar con justicia que contribuye mucho para mantener un clima de armonía en las organizaciones, es administrar la controversia pública en donde se llama al diálogo abierto y claro para que las partes en confrontación de opiniones alcancen mediante la comunicación el equilibrio de intereses para la solución justa de sus demandas. Así prevenimos la radicalización de opiniones y el posterior conflicto, que a pesar del diálogo, pueda no dejar conforme a alguna de las partes en litigio.

\subsubsection{Las Relaciones Públicas y el amor humano}

Al referirnos al amor humano, podríamos tomarlo desde diferentes facetas: el amor espiritual, el amor profesional, el amor por los valores, el amor paternal o maternal o el amor filial.

Desde el punto de vista profesional, debemos cultivar dos clases de amor: por el ejercicio de la profesión misma y por el prójimo. En los valores cristianos, es imperativo que todos tengamos amor por nuestro prójimo como lo tuvo Nuestro Creador y Nuestro Redentor al buscar librarnos del pecado.

El amor posee diversas definiciones también, según sea el punto de vista del cual se considere. En el caso de las organizaciones, dentro de la cultura de trabajo se cultiva el amor por el trabajo y el servicio, el cual consiste en que cada miembro de una empresa o institución trabaje al máximo y trate de dar lo mejor de sí para el bien de su organización, de sus públicos y por alcanzar la felicidad propia por saber que se actuó bien. Notemos que cuando nos referimos a dar lo mejor de nosotros como parte y organización misma a favor de nuestros públicos, afirmamos que todas las organizaciones deben tener no solamente amor por sus propios integrantes, sino más bien, por su prójimo reflejado en la sociedad que les permite desarrollarse y a quienes les debe todo cuanto son. 
Estas acciones mencionadas forman parte de las expresiones con las que las organizaciones puedan manifestar su amor por la sociedad que les permite crecer y desarrollarse. Evidentemente, las acciones de Relaciones Públicas son aquellas que cristalizan en la realidad este valor.

Entonces, podemos afirmar que actuar con amor implica, entre otras cosas: ser responsables, ser puntuales, ser consecuentes con nuestros actos, sentir la membresía de grupo, mejorar los canales de comunicación con nuestros públicos, colaborar con el desarrollo de nuestra sociedad, incentivar los valores morales en los demás, buscar los medios para lograr la mutua comprensión con nuestros públicos, y sobre todo, ser honestos e informar con la verdad. Todas estas expresiones que pueden desarrollar las organizaciones para expresar su respeto por la comunidad, reflejan el amor que pueden sentir por la sociedad a la que pertenecen.

Por tanto, siendo éstas manifestaciones de la conocida Responsabilidad Social y de la Calidad Total, se constituyen en objetivos que las Relaciones Públicas buscan alcanzar para la obtención del concepto favorable hacia las organizaciones.

De allí viene la máxima de las relaciones públicas: "Hacer las cosas bien y hacerlas saber", a: "Hacer las cosas bien, hacerlas saber y hacerlas sentir", tal como sucede en lo que denominamos amor: Tratamos de hacer lo mejor nuestras acciones para nuestro prójimo en el amor que podamos sentir por él y tratar de que nuestro prójimo nos comprenda y sienta junto con nuestra organización la satisfacción de poder compartir. Sin lugar a dudas, enorme reto que se constituya en el trabajo de las relaciones públicas en este siglo XXI.

\subsubsection{Las Relaciones Públicas y la verdad}

Consideramos que la verdad es el valor que se constituye en la piedra angular y básica del trabajo de las Relaciones Públicas en su esencia. En sí, dijimos que las relaciones públicas constituyen la "conciencia organizacional" y que ésta debe estar orientada hacia la moral y las buenas costumbres. Qué mejor que actuar siempre a la luz de la verdad para predicar con el ejemplo en el quehacer organizacional, y como consecuencia en el trabajo del hombre sea la profesión que cumpla.

La verdad está presente en todos los códigos de ética para el ejercicio de las Relaciones Públicas, y por ello se comprueba que nuestra labor para comunicarnos e interrelacionarnos adecuadamente con nuestros públicos es mediante la veracidad de las informaciones que les proporcionemos. No olvidemos que al tratar con nuestros públicos con la verdad, también estaremos 
respetando la dignidad que como seres humanos nos merecemos al tener derecho a ser informados adecuadamente y de no ser manipulados con informaciones tendenciosas que nos distraen de los verdaderos asuntos que nos conciernen para alcanzar nuestro progreso.

Senac (1996), afirmó que no podemos engañar a toda la gente por siempre, ya que la verdad siempre se descubrirá, se convierte a la vez en una realidad indiscutible que nuestra labor debe tomar en cuenta. Tarde o temprano las mentiras se descubren y éstas pueden destruir por completo a cualquier organización, de tal forma que resulta imposible volver a recuperar la confianza (o la pseudoconfianza) que tuvo la gente hacia estas organizaciones.

Un buen concepto no se puede construir sobre las mentiras, justamente porque éstas se descubren y tiran al suelo como un castillo de naipes lo que se deseaba aparentar. De aquí también dilucidamos con mayor claridad la diferencia entre las definiciones de "imagen" y "concepto". La primera, puede ser real o falsa, pero impactante y fácilmente puede cambiarse en la mente de nuestros públicos, ya que solo es un conocimiento referencial e incompleto. La segunda, en cambio, se basa en el conocimiento más allá de las apariencias físicas, sino en el aspecto íntimo de las organizaciones, hechos que son casi imposibles de tergiversar y de cambiar en la mente de las personas.

Las relaciones públicas indudablemente para lograr la confianza de los públicos de toda organización, más que imagen (que es solo un medio), deben tener como finalidad la obtención de un concepto favorable, pero éste debe estar basado en la verdad para que sea sólido, firme y que inspire la confianza antes mencionada. Qué mejor que actuar con transparencia, sin tener que ocultar acciones poco honestas, trabajar a "salto de mata" y no saber cómo explicar diversos hechos. Así no somos libres para presentarnos ante nuestros públicos, y la historia en nuestro mundo demostró muchos casos de organizaciones que por un tiempo fueron muy exitosas, pero al no actuar con la verdad, fueron descubiertas y cayeron hasta ser olvidados por la sociedad.

Las relaciones públicas buscan, al contrario, que las organizaciones sean abiertas (política del Kimono Abierto) y transparentes ante los ojos de la sociedad, sin tener que ocultar nada, y puedan trabajar con total libertad contando con la aprobación de la gente. Recordemos que nuestro Redentor dijo claramente al respecto: "La verdad os hará libres". 


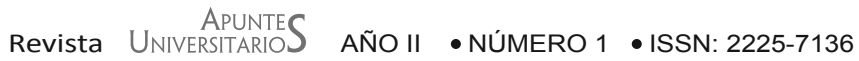

\section{Las Relaciones Públicas y su relación con las virtudes cristianas y humanas}

Isaacs (1991), comenta en su obra que las virtudes pueden aplicarse al trabajo de las relaciones públicas porque esta profesión es eminentemente de comunicación y de interrelaciones humanas expresadas entre las organizaciones y sus públicos.

Si las relaciones públicas son la "conciencia organizacional", entonces son las responsables de garantizar que las relaciones que mantengan las organizaciones con todos sus públicos sean dentro de los valores morales y las virtudes humanas para alcanzar el desarrollo de cada persona en perfecto respeto hacia su dignidad. A continuación veamos cómo las Relaciones Públicas pueden y deben desarrollar su trabajo dentro de estas virtudes que también deben practicar los cristianos para humanizar mejor nuestra labor en nuestra sociedad.

\subsection{Las Relaciones Públicas y la amistad}

Es una virtud que, por ser nosotros los seres humanos selectivos, no siempre llegamos a tenerlos con todos quienes nos rodean. La amistad surge porque podemos encontrar coincidencias profesionales, ideológicas, religiosas o simplemente personales con los demás. Esto ocasiona en muchos casos un sentimiento de simpatía y aprobación mutua, hecho que nos lleva posteriormente a querer identificarnos y ponernos en el lugar de la otra persona y velar por su bienestar o éxito.

En el caso de las organizaciones, pues como toda persona, también necesitan integrarse a su comunidad y pertenecer a ella. No lo lograrán si no muestran simpatía ni espíritu de colaboración para con el medio que las rodea. Es decir, necesitan hacerse querer y ser aprobadas por la comunidad en base a la búsqueda de intereses comunes que les permitan a ambas partes alcanzar sus respectivas metas equitativamente. Que logren comprenderse unos a otros y saber ayudarse mutuamente para afrontar mejor las adversidades que se puedan dar.

Eso es amistad, y las organizaciones así deben mostrarse ante sus públicos, siempre con vocación de comprenderlos y servirlos como la base de una unión franca y sincera. Las Relaciones Públicas son las encargadas de administrar estas políticas de coincidencias y amistad que deben mostrar todas las organizaciones hacia sus públicos, ya que son las que enseñan que ante todo, las organizaciones deben saber escuchar a sus públicos y una vez dado esto, tratar de sintonizarse con las expectativas e intereses de sus públicos. 
Las organizaciones deben mostrarse cordiales y con vocación de servicio ante sus públicos no solamente en tiempos de tranquilidad en donde aparentemente no existan problemas. Las organizaciones deben mostrar su verdadera amistad hacia la sociedad siendo solidarias y socialmente sensibles ante los problemas que la puedan afectar en los momentos difíciles que puedan presentarse, como por ejemplo: desastres naturales, apoyo a personas necesitadas y, sobre todo, saber tratar bien y preocuparse por los problemas de sus propios integrantes. Las relaciones públicas son las encargadas de llevar adelante esta política de acercamiento que deben tener las empresas para con la sociedad en general.

\subsection{Las Relaciones Públicas y la flexibilidad}

Ser flexibles consiste en saber cómo adaptarnos a los cambios que pueden presentarse en nuestra realidad. Estos cambios en nuestro mundo actual son muy rápidos, muchas veces violentos y se dan en todos los campos del quehacer humano, cambios a los que debemos adecuarnos con la misma velocidad a como se nos presenten de acuerdo a cada situación o realidad de cada organización. En muchos casos esta flexibilidad implica renunciar a criterios personales, por ejemplo como sucede actualmente, en donde tanto gracias a las relaciones públicas como al marketing, los dirigentes de las organizaciones que buscan su competitividad, han tenido que reconocer, después de mucho tiempo, que por la competencia son ahora los clientes quienes marcan las pautas de los cambios en las mismas organizaciones bajo el pensamiento de "el cliente tiene la razón", las organizaciones deben integrarse necesariamente con sus públicos.

Pero de allí es que el ser hombre viene alcanzando su desarrollo si lo aplica respetando sus valores, en caso contrario podría contribuir a su propia destrucción. Las relaciones públicas eminentemente se convierten en este caso los agentes de transformación social, tal como lo afirma Hernández (1996), comentando que las relaciones públicas modernas surgen como el faro que puede permitir llegar a un buen puerto a esos propósitos de integración. Ya que puede facilitar convergencias que posibiliten el desarrollo de las organizaciones y la realización de sus miembros, se hace necesario tener adecuados conocimientos de la estructura y dinámica de la realidad sociocultural para recrear ese universo con la visión de conjunto, desde una perspectiva holística que contraste con propósitos rígidos y cerrados". Evidentemente, las relaciones públicas, según esta afirmación, deben ser dinámicas, permitiendo así a nuestras organizaciones a saber comunicarse y escuchar mejor a sus públicos, comprender sus necesidades y expectativas y, en base a ello, apli- 
car los cambios necesarios para mantener sintonizada a la organización con sus públicos estando a la par con las demandas que ellos nos puedan hacer. Además, la práctica de esta virtud obliga a las relaciones públicas asumir una responsabilidad tan grande como es el de investigar y mantener permanentemente el contacto con cada clase de público, ya que los públicos son cambiantes, hecho que siendo nuestra naturaleza el combatir la monotonía y el buscar constantemente mejoras y más mejoras en nuestro nivel de vida, permite a las organizaciones tener una filosofía de trabajo orientada siempre hacia la constante búsqueda de la Calidad Total basándose en nuestra disposición para adecuarnos a los cambios que nuestra sociedad exige de nosotros como organización.

\subsection{Las Relaciones Públicas y la fortaleza}

La fortaleza puede definirse como la capacidad que podemos tener, tanto organizaciones como personas, ante situaciones adversas resistir y enfrentarlas para vencerlas, y en base a ellas hacer realidad proyectos grandes que beneficien a todos por igual.

La fortaleza nos hace ser verdaderos ganadores. Recuerdo aquí a un viejo proverbio chino que me impactó y versa así: "El verdadero triunfador no es aquél quien siempre gana las cosas fácilmente o con suerte, sino aquél quien sabe ponerse en pie y recuperarse de sus caídas". Como que a nuestros problemas hay que tomarlos como oportunidades de aprender y mejorar nuestra condición de seres humanos, hacernos más sensibles, más conscientes y ganar sabiduría. Diría además aquí que una persona quien tuvo la oportunidad de enfrentarse a diversos problemas y supo cómo enfrentarlos es mucho más madura y capaz que aquella que simplemente no los tuvo o que decidió rendirse y evitar enfrentarlos.

Igual pasa con las organizaciones. Ninguna organización, por más grande y poderosa que sea, puede jactarse de no tener algún problema o por no haber pasado en su historia por momentos difíciles.

La superación de los problemas a lo largo de su historia ha hecho posible que sean las empresas fuertes de hoy. Las Relaciones Públicas juega un papel preponderante en la solución de estos problemas, partiendo del punto de vista que los orígenes de éstos es la falta de una adecuada comunicación dentro y fuera de las mismas organizaciones. En Relaciones Públicas no podremos proyectar un concepto favorable hacia la sociedad si es que, en primer lugar, no hemos cimentado una buena comunicación entre todos y cada uno de los miembros de organización. Si hemos logrado esto, hemos dado un paso muy importante al lograr que nuestro propio personal se sienta iden- 
tificado con nuestra institución. Y será, justamente nuestro personal, aquel equipo de difusores de nuestra buena conducta que, a la larga, hará posible que nuestra sociedad comparta también, al igual que nuestra gente, ese buen concepto que tanto buscan las Relaciones Públicas en pro de la organización y de los públicos mismos.

Además, gracias a la comunicación estratégica que utilizan las Relaciones Públicas como su principal herramienta de trabajo, podemos no solo resolver problemas y adquirir experiencia sino, además, evitarlos y fortalecer con mayor facilidad la comprensión mutua entre todos los integrantes de la organización y de sus públicos ambivalentes y externos al mismo tiempo. No olvidemos que ésta es la piedra angular para lograr el desarrollo de nuestras organizaciones en la actualidad.

\subsection{Las Relaciones Públicas y la generosidad}

Ser generosos implica hacer acciones y políticas a favor de otras personas o públicos en forma desinteresada. Es más, hacer realidad estas acciones a favor de otros nos debe proporcionar satisfacción si tomamos en cuenta la necesidad de efectuar estos hechos a favor de nuestro prójimo, aunque ello implique esfuerzos adicionales por parte de nosotros.

En el caso de las organizaciones, empresas o instituciones, esta generosidad se expresa mediante la responsabilidad social que deben efectuar a favor de la sociedad que las acoge, sean sus integrantes clientes directos o no directos de nuestra organización. Las acciones de responsabilidad social están a cargo de las Relaciones Públicas porque estas acciones son una forma de comunicación que efectúan las organizaciones para expresar su gratitud hacia la sociedad misma por dejarla desarrollarse al interior de ella.

No nos cansamos de afirmar que toda organización está llamada a "hacer historia en la sociedad" en donde existe, convive y se desarrolla, porque ninguna organización que desee ser aceptada por el medio ambiente que la rodee puede permanecer indiferente ante los problemas y necesidades que ella tiene. Es más, las organizaciones no deben esperar a que la comunidad les pida ayuda; de ellas mismas debe nacer esa vocación de ayudar, y será así que lograrán ganarse el buen concepto que buscan para desarrollarse por parte de la comunidad.

Existen diversas formas en que las organizaciones, cumpliendo con su responsabilidad social mediante las Relaciones Públicas, puedan ser generosas con su propia gente y con la sociedad en general: 
- Una de ellas pueden ser las donaciones, tanto financieras como logísticas, en donde la organización obsequia dinero, artefactos o servicios que puedan ayudar a la población afectada a paliar o solucionar sus necesidades.

- Otra pueden ser los auspicios, en donde una organización, si bien no es la que organiza directamente la actividad de bien social, pero apoya a la organización principal para que pueda cumplir su propósito de ayuda social. Ejemplo: Si el Ministerio de Salud organiza una campaña gratuita de vacunación masiva para niños, una empresa privada cualquiera pudiese apoyar dicha campaña con la impresión de afiches, pancartas o con los servicios de movilidad necesarios para que el personal de dicho ministerio pueda llegar con mayor facilidad hacia aquellos sectores alejados de nuestro país que, justamente, son quienes más necesitan de nuestra ayuda.

- El Mecenazgo es una acción de Relaciones Públicas en donde una organización puede apoyar el desarrollo de "talentos" artísticos, deportivos o científicos en una comunidad. Estos "talentos" son personas quienes tienen diversas habilidades, pero que no pueden superar y desarrollar adecuadamente sus capacidades debido a sus carencias principalmente de índole económico. Éstos son presentados a menudo en reportajes que difunden prestigiosos programas de investigación periodística en la televisión a manera de reportajes humanos, en los cuales indirectamente se solicita a las empresas que los apoyen costeándoles sus estudios, investigaciones o actividades artísticas. Cuando una organización se encarga de financiar todos los gastos que impliquen que estas personas talentosas puedan desarrollar sus talentos, podemos decir que las organizaciones están desarrollando su responsabilidad social mediante el mecenazgo. No olvidemos que este término proviene de los "mecenas", personas acaudaladas quienes protegían y ayudaban a desarrollar los talentos de diversos artistas en la edad media, siendo uno de los artistas más beneficiados por un mecenas el escultor y pintor Miguel Ángel Buonarotti quien pintó los frescos de la Capilla Sixtina del Vaticano.

\subsection{Las Relaciones Públicas y la humildad}

Ser humilde consiste en reconocer sus cualidades y virtudes para ponerlos al servicio de los demás sin requerir el reconocimiento ni los halagos ajenos por estas acciones. 
Afirmamos que la humildad es a la vez también un valor cristiano muy apreciado, ya que nuestro mismo Redentor lo practicaba a cada momento, sobre todo cuando hacía milagros en beneficio de su prójimo al sanarles de diversas enfermedades. ÉL nunca dijo que "Yo te he sanado..." sino más bien que la fe de los demás fueron las causas de dichas sanaciones o milagros. ÉL mismo dijo: "El que se ensalza será humillado, mas el que se humilla será ensalzado". Esto da a entender claramente que quien se vanagloria y no es humilde, será rechazado; mas el quien es humilde y servidor, tarde o temprano será reconocido por los demás.

Las relaciones públicas, como la conciencia organizacional, deben practicar esta virtud en las organizaciones para que éstas, al cumplir con su responsabilidad social, no se estén jactando de las ayudas que ellas brindan a su prójimo. Una manera efectiva de ganarse el respeto por parte de los públicos es que la organización misma que efectúa acciones en bien de ellos es no vanagloriarse de estas acciones, no exagerar con las cosas magnificándolas y propagar por todos los medios lo bien que hizo la organización, ya que estaría cayendo dicha organización en una soberbia que, lejos de concitar el beneplácito público, generará rechazo por gran parte de nuestra comunidad y, por ende, un mal concepto.

Qué mejor dejar que sean los propios beneficiados que reconozcan las buenas acciones de las organizaciones. Con esto no queremos decir que las organizaciones no deban difundir sus buenas acciones, tal como lo dice la máxima de las Relaciones Públicas de "hacer las cosas bien y hacerlas saber". Es lícito que las organizaciones den a conocer a la sociedad sus acciones acertadas, pero no con exageración ni constantemente. Ser humilde es tener vocación de servicio y no anhelar deliberadamente los aplausos de la gente.

\subsection{Las Relaciones Públicas y la justicia (para el equilibrio de intereses)}

Practicar la justicia significa dar a todos y cada uno de nosotros lo que nos corresponda, ni más ni menos, en función del cumplimiento de nuestros deberes correspondidos por el respeto de nuestros derechos, en diversas facetas de nuestra vida cotidiana como estudiantes, como clientes, como padres, como empresarios como gobernantes y gobernados.

Las relaciones públicas al referirse a la justicia, pues buscan que las organizaciones a quienes asesoran también sean justas con sus públicos. Es importante crecer con la gente y no a costa de la gente, lo que implica que es lícito desarrollarnos y crecer, mas no en desmedro de los intereses de nuestros públicos internos o externos. Crecer con la gente significa precisamente ser "justos", dándoles a nuestros públicos la parte que les corresponda de 
nuestros éxitos como organizaciones. Ser justos también implica cumplir nuestros deberes para con la sociedad, como por ejemplo pagar impuestos y no usar artimañas para evadirlos, como también ser gratos con la sociedad y cumplir adecuadamente nuestra responsabilidad social.

Vemos una vez más que las relaciones públicas juegan un papel preponderante en este punto, ya que si desean que sus organizaciones sean bien vistas por la sociedad y tengan buen concepto por parte de ella, deben practicar la justicia, sin discriminar a nadie y compartir sus éxitos con todos aquellos quienes hicieron posible tales logros, es decir, con la sociedad misma.

\subsection{Las Relaciones Públicas y la laboriosidad}

Con respecto a la laboriosidad, es necesario que toda organización tenga una buena conducta hacia todos sus públicos trabajando ordenada y diligentemente con todas sus acciones encaminadas hacia el logro de sus objetivos y metas. La base de todo éxito radica en un trabajo constante y perseverante, que en muchos casos implica sacrificios y esfuerzos adicionales, pero que a mediano o largo plazo obtiene como recompensa el desarrollo y el reconocimiento de todos los demás.

Las relaciones públicas, al ser la conciencia organizacional, deben crear una cultura de trabajo en las organizaciones que motiven a todos y cada uno de sus integrantes a dar lo mejor de ellos, haciéndoles sentir que un trabajo concienzudo traerá progreso y bienestar, no solo para la organización, sino para todos y cada uno de ellos mismos. Aquí también entra a tallar el sentido equitativo de justicia que deben practicar los dueños y dirigentes de las organizaciones con su propio personal y con su comunidad.

No es positivo dormirse en sus laureles e invocar constantemente logros pasados. El mundo actual es cada vez más competitivo y la calidad total de hoy, simplemente será el punto de partida del mañana cuando existan mayores y más grandes exigencias. Al respecto, Monclús (1990), comenta: "Sonríe, que mañana será peor". Esto significa que nuestro éxito de hoy será rebasado mañana y que tendremos que superarnos más y afrontar nuevos retos. Ninguna organización que busque ser bien vista por la sociedad puede permanecer ociosa, ya que la exigencia de hoy de mantenernos sintonizados con nuestros públicos hace posible que las organizaciones no pierdan el paso y trabajen cada vez más en forma más constante y disciplinada para estar a la par con las exigencias de nuestros públicos de hoy, quienes cambian constantemente y se vuelven cada vez más exigentes. 


\subsection{Las Relaciones Públicas y la lealtad}

Tal como lo señala Ramos (1998), ser leales implica aceptar y respetar nuestra adhesión a otros, sean amigos, jefes, familiares, patria, religión e instituciones, etc.", lo mismo que defender los valores que encierran ante cualquier circunstancia, hecho que implica, incluso, a veces renunciar a intereses personales.

Las relaciones públicas, al respecto, deben cultivar la lealtad que deben mostrar las organizaciones hacia sus públicos, sean internos, ambivalentes o externos, anteponiendo sus intereses sobre los de la propia organización misma. Ser leales, en este caso, implica no traicionar los fines para la que fue constituida la organización, la que se supone es para servir y cumplir un rol constructivo en la sociedad en beneficio de todos sus integrantes. Ésta se encuentra incluida en la misión la cual muestra el papel que cumple toda organización para bien de toda la sociedad, lo que incluye a la comunidad, sean éstos cliente o no. Las relaciones públicas, en virtud de ello, deben trabajar asesorando a los más altos niveles jerárquicos de las organizaciones para que ejecuten acciones y planifiquen programas que cumplan con los preceptos de la misión que tienen en la sociedad. Si establecemos el equilibrio de intereses basados en la verdad y la transparencia en nuestro accionar en donde tanto organización y públicos salgan beneficiados, podemos decir que actuamos lealmente ante nuestros públicos. Si solo la organización obtiene beneficios mas no sus públicos, no podríamos hablar de acciones leales de la organización hacia su entorno.

\subsection{Las Relaciones Públicas y la perseverancia}

Ser perseverante implica no dejarse abatir por los obstáculos que se nos presenten en el difícil camino por alcanzar las metas deseadas, motivando a todos los integrantes de la organización a no bajar la guardia ni los ánimos por la demora de nuestros logros.

En virtud de ello, las Relaciones Públicas sirven como el eje motivador que oriente el trabajo en conjunto que deben seguir todos y cada uno de los miembros de la organización. Y si logramos nuestras metas, nunca reducirse al conformismo. La exigencia del mundo de hoy por la tan ansiada obtención de la CALIDAD TOTAL nos exigen día a día trazarnos metas cada vez más altas, hecho por lo que acertadamente el Cellino (1996), denominó al relacionista público como "La Jirafa: Con metas altas y al mismo tiempo con los pies bien puestos sobre la tierra. 
Perseverar, por lo tanto, es una forma de vida que nos impulsa a ser cada vez mejores, tanto como personas como profesionales en diversas facetas que podamos tener en nuestras vidas. Lo mismo las organizaciones, deben tener a un asesor que les dé un motivo para desarrollarse impulsado por el deseo de servir cada vez mejor a todos sus públicos. Ese asesor responsable del espíritu de perseverancia y superación se llama relacionista público.

\subsection{Las Relaciones Públicas y la prudencia}

La prudencia es fundamental en la práctica de las Relaciones Públicas, ya que necesariamente al establecer relaciones con los demás, tanto en forma personal como en forma organizacional, debemos hacerlas fuera de todo prejuicio o expresión desmedida de nuestras emociones, causantes muchas veces de exabruptos que pueden fácilmente cortar una posibilidad de establecer contactos favorables para nuestra organización y nuestros públicos al mismo tiempo.

Actuar con prudencia es el camino que siempre debe optar el relacionista público. Por su constante contacto con diversas clases de públicos pueden surgir, en algunos casos, tensiones por imponer intereses. En estos casos la actuación correcta del relacionista será evitar en todo momento responder altisonantemente con su interlocutor, más bien procurar ponerse en el lugar de él y tratar de comprenderlo para poder equilibrar los argumentos de él y los nuestros para así tratar de tomar una decisión que sienta nuestro receptor que favorece a ambas partes. Interviene aquí la inteligencia emocional del profesional en la cual nos permite convertir un principio de conflicto en una oportunidad de amistad.

Ser prudente, además de tomar decisiones equilibrando intereses, también incluye no rebajarse a los mismos niveles de comportamiento que puedan presentar algunas personas no bien educadas. Las relaciones públicas, en virtud de de ello, no solo deben actuar cautelosamente al tratar a todos sus públicos como su función específica, sino que además también deben capacitar e instruir a todos y cada uno de los miembros de la organización para que conozcan el trato cordial y equilibrado, ya que deben concientizar a cada uno de ellos que representan la imagen y el posterior concepto favorable que la organización desea conseguir para su desarrollo.

\subsection{Las Relaciones Públicas y el respeto}

Respetar significa actuar para conseguir nuestros objetivos y metas personales ejerciendo nuestros derechos de progresar, pero sin vulnerar los derechos de los demás perjudicándolos. 
Las relaciones públicas orientan el trabajo de las organizaciones a desarrollarse conjuntamente con los intereses de sus públicos en perfecta armonía con sus derechos. Dentro de este valor, podemos mencionar también como respeto que le deben las organizaciones a sus públicos la protección del medio ambiente y la ecología. Es legítimo que las organizaciones se desarrollen, crezcan y produzcan, pero sin destruir las condiciones ambientales que aseguren la vida y el bienestar de su propia gente ni la de la sociedad en general. A eso nos referimos cuando afirmamos que las Relaciones Públicas orientan el trabajo de las organizaciones para "crecer con la gente y no a costa de la gente".

Actualmente las organizaciones se orientan mucho hacia la obtención de la denominada "Calidad Total" mediante certificaciones ISO 9000, 9001,14001 , las cuales se fundamentan justamente en que como las organizaciones cumplen sus fines respetando el derecho a la vida y la salud mediante el cuidado del medio ambiente. Esto también es un punto favorable para la obtención del buen concepto que persiguen las Relaciones Públicas a favor de las organizaciones.

\subsection{Las Relaciones Públicas y la sinceridad}

Las relaciones públicas deben fomentar una política de comunicación de doble vía con nuestros públicos basándose en la expresión de lo que realmente pensamos, sentimos y deseamos sin encubrir ninguna intención que pueda ser mal interpretada posteriormente por ellos.

Con la sinceridad se logrará que las organizaciones y sus públicos se comprendan mutuamente y así que exista el mejor de los conceptos a favor de las primeras. Si podemos cumplir con lo que nuestros públicos nos piden, en buena hora; en caso contrario como organización debemos explicar a nuestros públicos las razones "reales" de no poder satisfacer sus necesidades, pero nunca debemos quedarnos callados en este caso. Quedamos mejor ante los ojos de nuestros públicos al explicar francamente nuestras razones de no poder cumplir con algo que ellos deseaban, a que no decir nada y dejar en incertidumbre a nuestros públicos. Para las Relaciones Públicas, el silencio no es un buen negocio porque da lugar a la formación de rumores que pueden destruir muchos años de esfuerzo que se halla hecho por construir nuestro prestigio. 


\subsection{Las Relaciones Públicas y la sobriedad}

Las relaciones públicas deben asesorar a todos los integrantes de las organizaciones a que tengan conductas razonables y serias frente a las exigencias y expectativas de nuestros públicos. Esto exige que cada miembro que labora en una empresa o institución actúe coherentemente con la misión y visión que tiene la propia organización cumpliendo con seriedad y a la vez con amabilidad con sus funciones, de tal manera que logren satisfacer los requerimientos que puedan presentar nuestros clientes o la sociedad en general.

Actuar con moderación, con racionalidad, con lógica y sin exageración para encontrar soluciones que beneficien a las organizaciones también es un punto importante de referencia para que en la sociedad nuestros públicos tengan un buen concepto de nosotros.

\subsection{Las Relaciones Públicas y la sociabilidad}

Ser sociable implica generar los canales más adecuados para relacionarnos eficiente y eficazmente con distintas y grupos sociales, mediante nuestra preocupación e interés por lo que ellos son, por lo que dicen, por lo que piensan, por lo que hacen y por lo que sienten.

Al igual que las personas, las organizaciones son entes eminentemente sociales, por lo que no solamente viven, sino que "conviven" y requieren del entorno que les rodea para alcanzar sus objetivos. En virtud de esto, el trabajo fundamental de las Relaciones Públicas es hacer que las empresas e instituciones sean sociables con sus comunidades, mostrando el debido interés y respeto hacia la gente. Ninguna organización el concepto favorable si es que no se relaciona adecuadamente con sus públicos.

\section{Conclusión}

Hebreos, capítulo 11, versículos 1 y 2, declara: “Es pues, la fe la certeza de lo que se espera, la convicción de lo que no se ve", "Porque por ella alcanzaron buen testimonio los antiguos".

Si nos ponemos a pensar sobre esta definición tan certera de lo que significa la fe, podemos darnos cuenta que ella nos permite tener un motivo por qué vivir y luchar constantemente por alcanzar nuestras metas en esta vida, dándole así un sentido a nuestra existencia.

Llevándolo al campo organizacional, podemos afirmar que muchas grandes organizaciones empezaron hace pocos o muchos años atrás simplemente gracias a la fe que tuvieron sus fundadores al creer en algo que, en 
aquellos tiempos, todavía no vieron concretado. Esto lo alcanzaron porque creían en nuestra sociedad, específicamente la peruana que en los últimos treinta años pasó por momentos difíciles en su historia, hecho que motivó a que muchas organizaciones hayan optado por el camino más fácil de llevar sus industrias al exterior, siendo pocas las que apostaron por nuestro medio.

El caso de la corporación peruana Wong, cuyos fundadores iniciaron hace muchos años un sueño que hoy se convirtió en la cadena de supermercados más grandes de Perú. Todo empezó en una pequeña bodega en el distrito limeño de San Isidro de propiedad de un inmigrante asiático quien, con mucha disciplina y visión de futuro, efectuó innovaciones en nuestro medio adelantadas a su tiempo, como por ejemplo el ser la primera bodega que ofrecía el servicio delivery para los clientes aledaños a su negocio. En 1983 empezó a cristalizarse uno de los proyectos más ambiciosos de la historia comercial del Perú, cuando los hijos de E. Wong abrieron el primer supermercado con el mismo nombre de su padre en el distrito que los vio crecer.

Han transcurrido poco más de veinte años desde aquel hecho, y hoy esta organización se ha convertido en una exitosa corporación conformada por los supermercados e hipermercados Wong, Metro y Eco Almacenes, que en conjunto suman más de treinta sucursales en Lima. Y todavía siguen creciendo sostenidamente llevando sus productos a varios rincones de nuestra ciudad capital.

¿Cómo lograron salir de la nada estos exitosos empresarios? La respuesta que se nos viene a la mente, es que lo hicieron trabajando con mucho optimismo y fe en nuestro país, a pesar de los años difíciles en el aspecto económico en que nos tocó vivir.

Si estos empresarios no hubiesen tenido fe, no se habrían arriesgado a invertir en nuestro medio, quitándonos la oportunidad de tener una empresa que cada vez busca su calidad total. La fe nos ayuda a seguir adelante a pesar de las dificultades que nos puedan rodear, que aparentemente parecen insolubles a primera vista, pero que siendo muy acuciosos, pueden derivar en una excelente oportunidad de motivarnos y "madurarnos" para seguir adelante.

A la luz de estas afirmaciones, las relaciones públicas como en estos casos de éxitos empresariales, juegan un papel muy importante. Siendo las relaciones públicas la conciencia organizacional, se convierte en un factor de motivación y entusiasmo que puede conllevar a todos los integrantes de las organizaciones a creer más en sus empresas, en sus propias capacidades de desarrollo, en la aceptación que deben tener por parte de sus públicos, entre otros. 
Las relaciones públicas, en tal sentido, son las encargadas de sembrar esa fe en todos los miembros de las organizaciones conjuntamente con sus respectivos públicos externos y ambivalentes, generando así un clima de armonía producto de la utilización adecuada de los canales, técnicas y herramientas de comunicación que hagan posible la identificación y la comprensión hacia los objetivos de las organizaciones propiamente dichas. Sembrar esa fe en todos y cada uno de los públicos, no es tarea fácil, ya que requiere de un proceso paciente y metódico de comunicación de doble vía que genera un feedback que se proyecte a la sociedad en general. El secreto está en la investigación que efectúan las organizaciones para conocer mejor lo que sus públicos desean. En otras palabras, compartir con ellos nuestras metas y objetivos, y si nosotros como organización trabajamos con fe en la sociedad, la sociedad en sí nos devolverá esa fe concretizando nuestros objetivos en forma conjunta en armonía y aceptación.

Para que una sociedad alcance su desarrollo, es preciso que las organizaciones que se desarrollen en ella lo hagan con fe en ella misma. Con esa convicción de creer en algo que todavía no se ve, es la que nos impulsa a tener metas, objetivos y misiones claras que nos guiarán por la senda del progreso. $\operatorname{Sin} \mathrm{fe}$, sin esperanzas, sin objetivos ni metas, es imposible que alguna persona $u$ organización encuentre sentido a su existencia o que pueda alcanzar algo en esta vida.

Las relaciones públicas por su carácter de conciencia organizacional, son las motivadoras a que todos y cada uno de los públicos que forman parte o no de la organización, trabajen en conjunto en la búsqueda del desarrollo.

István János Kovács Halay

Universidad Peruana Unión email: istvankovacs73@yahoo.com 
István János Kovács Halay

\section{Referencias}

Castro, R. (1998). Ética profesional. Lima: Ediciones Universidad de San Martín de Porres.

Casiodoro de Reina (1960). La Biblia. EUA: Sociedades Bíblicas Unidas.

Frondizi, R. (1998). Ética profesional. Lima: Editorial Universidad de San Martín de Porres.

Hernández, E. (1996). Avances, tendencias y desarrollo de las Relaciones Públicas con visión del siglo XXI. Primer Foro Iberoamericano de Relaciones Públicas. Lima: Ediciones Universidad de San Martín de Porres.

Isaacs, D. (1991). La Educación de las virtudes cristianas. Pamplona: Ediciones EUNSA.

Monclús, J. (1990). Modelos sobre Relaciones Públicas. Barcelona: Ediciones Vicens - Vives.

Senac, R. (1996). Apuntes sobre relaciones públicas. XXI Congreso Interamericano de Relaciones Públicas. Instituto Chileno de Relaciones Públicas - ICREP. Santiago de Chile. 